\title{
BASIS DATA SEMU MENGGUNAKAN LEMBAR KERJA ELEKTRONIK PADA SISTEM OTOMATISASI PERKANTORAN
}

Feri Sulianta

Teknik Informatika, Fakultas Teknik, Universitas Widyatama

feri.sulianta@widyatama.ac.id

\section{ARTICLE REPORT}

\section{Article annals:}

Received 20 $0^{\text {th }}$ September 2017

Received in revised form $2^{\text {nd }}$ October 2017

Accepted $24^{\text {th }}$ October 2017

\section{Keywords:}

Office Automation System

Pseudo Database

Electronic Worksheet

Automatic

\begin{abstract}
The development of information technology nowadays encourages users to use the software appropriately so that commercial software can be maximally empowered that contribute to the efficiency and effectiveness of the job. To support its work, users use Microsoft's Microsof Excel Office Automation System worksheet commonly used by end users for clerical, repetitive and independent work.

Microsoft Excel applications are generally used for office worker, clerical computation and users generally use only a portion of the features of some features owned by the application. In this case, the user can maximize the ability of Excel by creating an interactive pseudo database using only Microsoft Excel, so users can organize data with automated database schema. It is intended for time efficiency and also improves the data security factor of human error in handling data.
\end{abstract}

@ 2017 ASMTB PRESS

\section{Pendahuluan}

Microsoft Excel saat ini sudah mengalami banyak perubahan antar muka aplikasi, perubahan besar-besaran dimulai sewaktu dilirisnya Microsoft Office versi 2007. Perubahan yang teralamati jelas adalah antar muka ribbon yang praktis, sehingga user tidak akan lagi dibingungkan untuk mengelola data karena tool-toolnya dikelompokan tersendiri berdasarkan alokasi ribbon dan ditempatkan berkelompok dengan tool-tool lain yang dapat digunakan berdasarkan status tool yang aktif saat ini, dalam artian, tool 'akan di-disable' jika tidak terelasi dengan pengerjaan user saat ini.

Lembar kerja saat ini memiliki daya tampung data yang semakin besar, hal ini yang membuat Excel memiliki kemampuan yang serata dengan basis data skala menengah dalam menyimpan data. Tidak seperti para pengguna Excel pada umumnya yang hanya menggunakan spreadsheet atau lembar kerja elektronik sebagai media kerja, 'Programmer Excel' yang dikenal sebagai End User level pemrograman dapat menggunakan fitur Excel yang lebih kaya fitur dan kompleks, mereka menggunakan kode pemrograman sebagai medianya. Kode pemrograman ini identik dengan bahasa pemrograman Visual Basic. Bahasa pemrograman Visual Basic ditambahkan pada Excel yang dikenal dengan nama Visual Basic Application (VBA) yang user friendly. VBA sangat identik dengan bahasa pemrograman Visual Basic, hanya saja dalam aplikasi Excel, VBA di rancang agar mudah digunakan user tanpa harus memahami bahasa pemrograman layaknya seorang programmer 
profesional, meski hasil yang dibuat VBA cukup baik dan memadai untuk skala end user. Fitur makro yang mampu menghasilkan rutin pemrograman dengan cepat dan membuat aplikasi lebih interaktif (Abdulkadir, Hassan., Matthew, Sunday., Onawola, Hassan., 2003 ; P, Anuradha., 2000). Terdapat pula fitur OLE Object (Object Linking and Embeding), yakni elemen-elemen yang dibandang sebagai obyek serta fitur ini akan menjembatani data berbeda dengan format file yang berbeda agar dapat saling berbagi pakai informasi (Shang-Chelin., Kavous, Roumina., Dam, Fadlalla., H, Walter., H, Enricks., 2002 ; USDA, 2007).

\section{Metode}

Untuk mempercepat dan mempermudah dalam proses seleksi, akan dibuatkan alat bantu yang dapat dijalankan dengan sistem komputerisasi. Penggunaan alat bantu dengan sistem komputerisasi diharapkan dapat menyelesaikan proses seleksi administrasi dengan lebih cepat, lebih rapi dan lebih akurat dibandingkan proses seleksi administrasi yang dilakukan secara manual. Salah satu alat bantu yang dapat digunakan untuk keperluan tersebut adalah aplikasi Seleksi Penerimaan Karyawan yang dibuat menggunakan Excel. Aplikasi dibuat dengan menciptakan pseudo basis data atau basis data semu pada lembar kerja elektronik Excel yang memiliki kemampuan yang setara dengan aplikasi basis data (Sulianta, 2007; Sulianta, 2010).

Dasar pertimbangan pembuatan aplikasi pseudo basis data menggunakan Excel adalah banyaknya fitur handal Excel yang dapat langsung diterapkan sehingga mempermudah dalam pembuatan aplikasi. Sebagai contoh, Excel menyediakan fitur formula dan fungsi yang dapat melakukan berbagai model perhitungan dengan tingkat ketelitian dan keakuratan yang tidak perlu diragukan lagi. Fitur tersebut dapat langsung digunakan dalam aplikasi sehingga tidak perlu membuat kode program perhitungannya terlebih dahulu. Beberapa teknik yang akan diterapkan dalam membuatan pseudo basis data ini yakni: Obyek Pada Excel, Script Visual Basic Application, dan Antar muka lembar kerja elektronik Excel sebagai platform (Sulianta, 2011; Sulianta, 2012).

Dalam kasus ini PT. XYZ membutuhkan beberapa karyawan untuk mengisi posisi marketing, produksi dan administrasi. Pelamar yang lolos seleksi administrasi dan berhak mengikuti test selanjutnya adalah para pelamar yang memenuhi kualifikasi yang ditetapkan perusahaan sebagai berikut:

Tabel 1. alokasi kualifikasi yang digunakan sebagai acuan kategorisasi data dalam pseudo basis data

\begin{tabular}{|l|c|c|c|}
\hline \multicolumn{1}{|c|}{ Persyaratan } & Marketing & Produksi & Administrasi \\
\hline Pendidikan & D3 & D3 & S1 \\
\hline Umur & $<25$ & $<30$ & $<25$ \\
\hline IP & $>2,75$ & $>2,99$ & $>3,00$ \\
\hline Gender & Pria & Pria & Wanita \\
\hline
\end{tabular}

Beberapa fitur yang harus dibuat dalam menciptakan Pseudo Basis Data adalah sebagai berikut:

- Membuat Fungsi Seleksi: Fungsi Seleksi digunakan untuk memudahkan penilaian hasil seleksi pelamar, apakah lolos atau tidak lolos. Argumen yang dibutuhkan dalam fungsi Seleksi adalah jabatan, pendidikan, umur, IP dan gender. Skrip untuk fungsi seleksi dibuat mengacu pada Visual Basic Application.

- Worksheet Database: Aplikasi seleksi penerimaan karyawan mempunyai 2 buah worksheet, yaitu worksheet form dan worksheet database. Worksheet Database merupakan worksheet yang digunakan untuk menampung data pelamar. Ada lima hal yang juga harus dipertimbangkan dalam tata kelola worksheet ini, yakni: 
- Menyaring Data (Filter): lakukan penyaringan data dalam database sehingga record data yang ditampilkan hanyalah record data yang memenuhi kriteria yang ditentukan. Penyaringan data dalam aplikasi akan sangat membantu, terutama untuk menampilkan hasil pencarian pelamar berdasarkan kata kunci nama pelamar.

- Membuat Nama Range: Nama range dibuat untuk mempermudah penggunaan Macro dalam aplikasi. Nama range yang akan dibuat adalah Database, NamaPelamar, Jabatan dan HasilSeleksi. Nama range Database bersifat statis, sedangkan NamaPelamar, Jabatan dan HasilSeleksi bersifat dinamis.

- Conditional Formatting: Fitur Conditional Formatting digunakan agar tampilan database lebih menarik dan informatif, misalnya persyaratan pelamar yang tidak sesuai dengan ketentuan perusahaan akan ditampilkan dengan teks berwarna merah.

- Validasi Data: Fitur Validasi Data dalam aplikasi digunakan untuk meminimalkan kesalahan pengguna ketika menginput data. Dengan menggunakan fitur validasi data, pengguna hanya dapat menginput data yang diperbolehkan.

- Pengaturan Pencetakan Database: Pengaturan pencetakan basis data dilakukan agar database hasil cetakan mampu memberikan informasi yang mudah dipahami untuk setiap field dan record data pelamar.

- Input Data Secara Manual: Penginputan data pelamar dilakukan secara manual melalui worksheet Database. Pengguna pada umumnya lebih menyukai input data secara manual karena hasil proses input data dapat dilihat secara langsung.

- Worksheet Form: Untuk memudahkan input, edit, menghapus atau melakukan pencarian record data dalam basis data, fitur Macro dapat ditambahkan sehingga prosesnya akan dilakukan secara otomatisas. Agar lebih interaktif, dapat pula menambahkan tombol untuk menjalankan yang dibuat dalam worksheet Form.

- Menambahkan Judul Form: Agar lebih menarik dan informatif, maka dalam Form perlu kita tambahkan judul form.

- Keterangan dan Kotak Isian Data: Keterangan dan kotak isian data yang tambahkan ke dalam worksheet Form digunakan untuk menampilkan data dalam database.

- Menambahkan Tempat Penampung Tombol: Gunak memunculkan faktor interaktif, dilakukan penambahan tombol untuk menginput, mengedit, menghapus, menavigasi atau mencari record dalam database. Tombol tersebut dialokasikan dalam range yang terdapat dalam worksheet Form

- Conditional Formatting dan Validasi Data: Tujuan penggunaan fitur conditional formatting dan validasi data dalam worksheet Form pada prinsipnya sama dengan penggunaan fitur conditional formatting dan validasi data dalam worksheet Database.

- Menambahkan Tombol: Dalam aplikasi seleksi penerimaan karyawan, akan di tambahkan 10 tombol ke dalam worksheet Form yaitu tombol <First, $\langle<\rangle>$,, Last $\rangle$, Cari, Cetak, Input, Edit, Delete dan Reset.

- Membuat Form Cari Pelamar: Form Cari Pelamar digunakan untuk mencari biodata pelamar berdasarkan kata kunci nama pelamar yang dimasukkan. Pencarian biodata pelamar akan langsung terupdate ketika ada perubahan pada kata kunci pencarian.

Sampel skrip pemrograman Visual Basic Application yang dibuat untuk mengakses pseudo basis data pada lembar kerja elektronik:

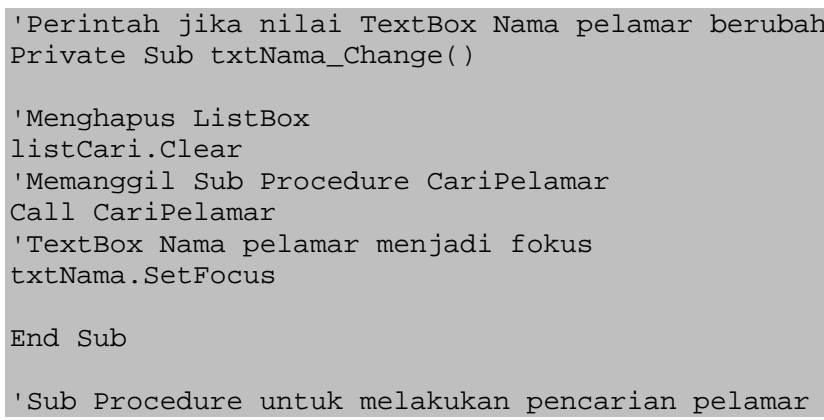




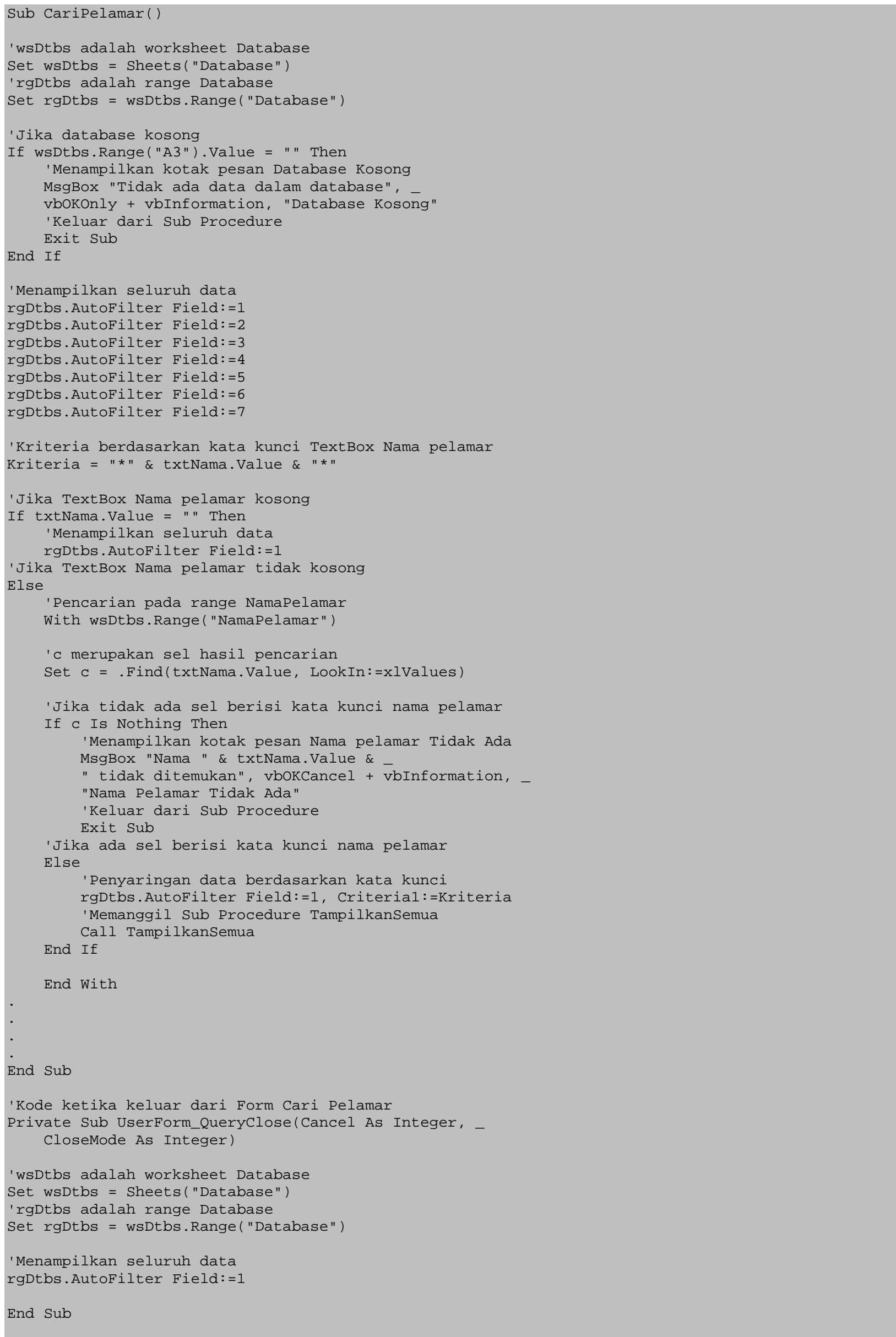


- Menambahkan Tombol Cetak: Tombol Cetak digunakan untuk mencetak database. Hal ini dibuat untuk mengetahui detail informasi seluruh pelamar dengan mudah setelah database tersebut dicetak.

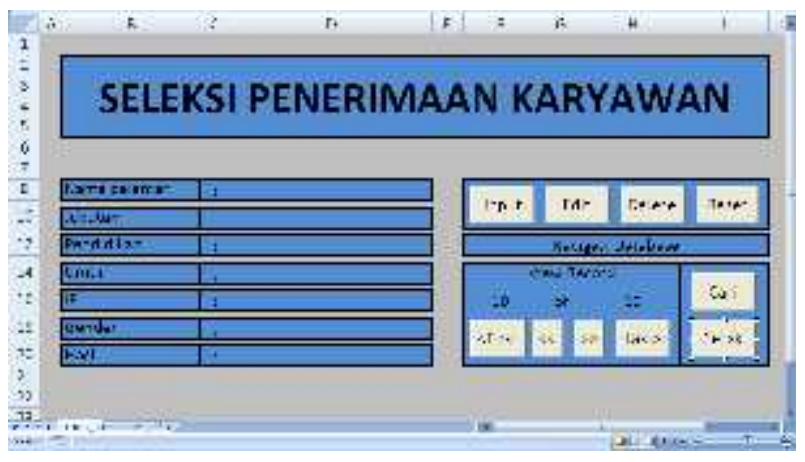

Gambar 1. Menambahkan tombol cetak

- Proteksi Worksheet: Proteksi aplikasi seleksi penerimaan karyawan dilakukan agar worksheet Form tidak dapat dimodifikasi.

\section{Hasil Pembuatan Aplikasi}

Perihal proses pembuatan aplikasi pseudo basis data siap pakai, sebelum menggunakan aplikasi basis data, tombol Design Mode yang terdapat dalam tab Developer grup Controls dikondisikan tidak aktif.

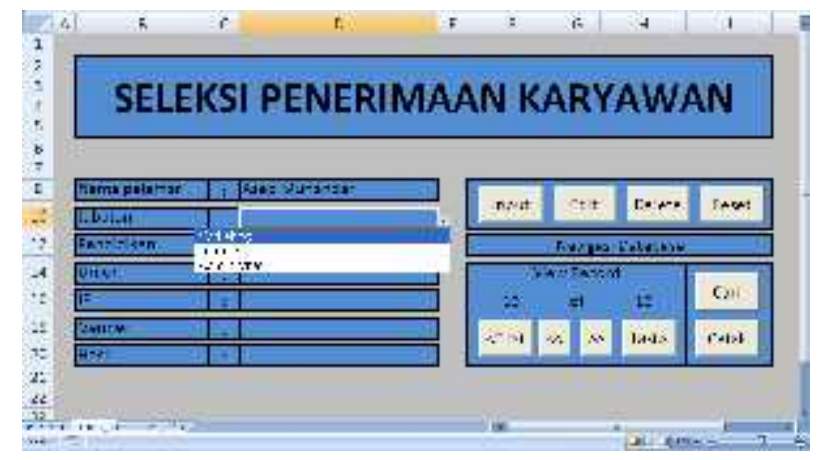

Gambar 2. Memilih jabatan yang dilamar pada sel D10

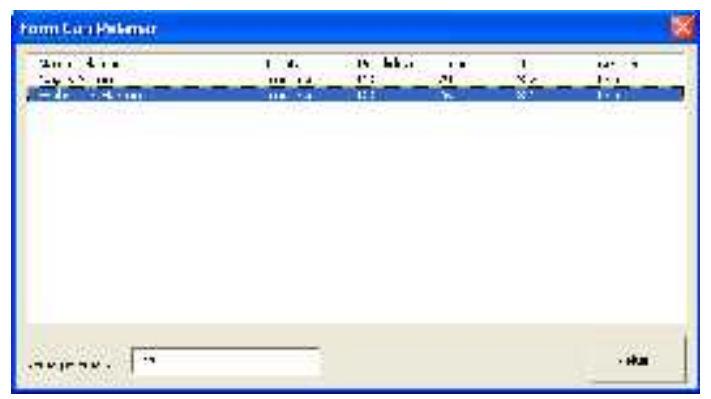

Gambar 3. Memilih biodata yang akan ditampilkan

Dipercontohkan, user dapat meng-edit biodata pelamar apabila terjadi kesalahan saat menginput data. Pemilihan nomor record yang akan diedit menggunakan tombol navigasi atau dengan menggunakan Form Cari Pelamar. Dapat dilakukan perbaikan yang diperlukan kemudian ditindaklanjuti dengan tinjauan kelayakan melalui memilih tombol Edit sehingga akan tampil antarmuka pengeditan Edit Record. 


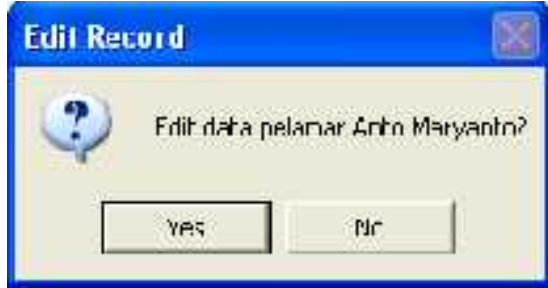

\section{Gambar 4. Kotak pesan Edit Record}

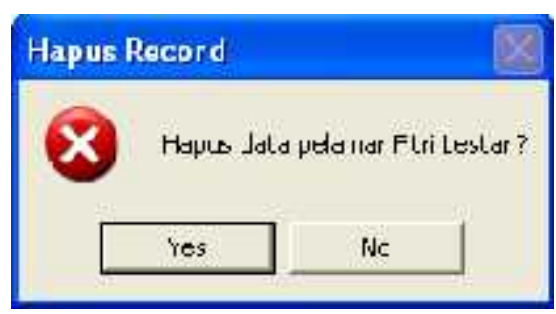

Gambar 5. Kotak pesan Hapus Record

\section{Simpulan}

Penggunaan Microsoft Excel sebagai Office Automation System memberikan sejumlah keuntungan, terutama dengan mengaplikasikan pseudo basis data pada spreadsheet elektronik, yakni: (1) Menghemat waktu: Meskipun Excel menawarkan formulasi dan berbagai tool yang memudahkan, meminimalisir waktu pengerjaan lebih efisien lagi, misalnya : Formulasi yang dibuat menggunakan fungsi-fungsi Excel dapat disertakan dalam program dan pekerjaan berulang dapat diprogramkan dengan aturan pemrograman yang terstruktur. (2) Standarisasi: Mendukung beragam format file dan kompatibel jika dokumen Excel dipakai bersama-sama dan berbagi data. Hal ini memunculkan problem ambiguitas, perbedaan variasi format dan style yang menyulitkan. Dengan adanya standar yang dibuat dengan pemrograman, maka struktur pengerjaan baku pada lembar kerja akan tetap terpelihara dan produktifitas pekerjaan akan meningkat. (3) Mengurangi error: Excel menyediakan fitur auto detect untuk mendeteksi kesalahan penulisan formula, tetapi jika muncul kesalahan logika, maka fitur auto detect tidak berlaku. Dengan pemrograman, error program dan logika dapat diminimalisir atau bahkan bebas kesalahan. (4) Kemampuan menangani data: Jika membuat suatu aplikasi penanganan data menggunakan bahasa pemrograman, file-file data berdiri sendiri-sendiri dan dialokasikan terpisah, termasuk pula aplikasi yang dibuat untuk mengaksesnya. Data-data Excel disimpan sepenuhnya pada lembar kerja (pada sel) Excel, semakin banyak data yang disimpan pada lembar kerja maka file Excel semakin besar. Selain itu keunggulan Excel dalam menangani ragam tipe data, Excel memiliki fitur bahasa pemrograman, dan sehingga Excel dapat diaplikasikan lebih lanjut di level pemrograman tingkat end user, dalam hal ini pemrograman pseudo basis data.

Berbagai komponen Object Linking and Embeding (OLE Object) dapat ditambahkan dalam Basis Data Semu untuk membuat antarmuka aplikasi yang lebih user friendly dan interaktif sehingga user dapat meminimalisir pengaksesan manual data pada lembar kerja elektronik. Pengetahuan saksama perihal Office Automation System akan membekali pekerja perkantoran dan juga sekretaris dalam pekerjaan di perkantoran yang sifatnya individual dan mandiri. 


\section{Daftar Pustaka}

Abdulkadir, Hassan., Matthew, Sunday., Onawola, Hassan. (2003). The Application of Visual Basic Computer Programming Language to Simulate Numerical Iterations. Department of Mechanical Engineering, Federal University of Technology, Minna. http://ljs.academicdirect.org/A09/125_136.htm

P, Anuradha. (2000). Automated Circulation System Using Visual Basic 6.0. Annals of Library Science and Documentation. Vol 4. No. 1.

Shang-Chelin., Kavous, Roumina., Dam, Fadlalla., H, Walter., H, Enricks. (2002). Integrating Data from Legacy Systems Using Object Linking and Embedding Technology: Development of a Reporting System for Heavy Metal Poisoning Results. Journal of the American Medical Informatics Association Volume 7 Number 4.

Sulianta, F. (2007). Cara Mudah Menjadi Programmer Excel. Penerbit Elexmedia Komputindo. Jakarta.

Sulianta, F. (2010). Tip dan Trik Programmer Macro Excel Profesional. Penerbit Andi. Yogyakarta.

Sulianta, F. (2011). Excel Intelligent - Cara Pintar Membangun Strategi Marketing. Penerbit Elexmedia Komputindo. Jakarta.

Sulianta, F. (2012). OLAP Excel. Penerbit Elexmedia Komputindo. Jakarta.

USDA - U.S Department of Agriculture md - natural resources conservation service AutoCAD Carlson Software Instructions. (2007). Object Linking and Embedding (OLE). MD-CS-55Object Linking and Embedding.

https://www.nrcs.usda.gov/Internet/fse_documents/nrcs144p2_025019.pdf 